\title{
Comparison between an Ascenda and a silicone catheter in intrathecal baclofen therapy in pediatric patients: analysis of complications
}

\author{
Francesco Motta, MD, and Clara Eleonora Antonello, PT \\ Department of Paediatric Orthopaedics, "V. Buzzi” Children's Hospital, Milan, Italy
}

OBJECTIVE In this single-center study the authors investigated the complications occurring before and after the introduction of the new Ascenda intrathecal catheter (Medtronic Inc.) in pediatric patients treated with intrathecal baclofen therapy (ITB) for spasticity and/or dystonia.

METHODS This was a retrospective review of 508 children who had received ITB, 416 with silicone catheters in the 13 years between September 1998 and September 2011 and 92 with Ascenda catheters in the 3 years between September 2011 and August 2014. The authors evaluated major complications such as infections, CSF leaks treated, and problems related to the catheter or pump, and they compared the 2 groups of patients who had received either a silicone catheter or an Ascenda catheter implant.

RESULTS One hundred twenty patients in the silicone group (29\%) and 1 patient in the Ascenda group $(1.1 \% ; p<0.001)$ had a major complication. In the silicone group 23 patients (5.5\%) were affected by CSF leakage and 75 patients (18\%) experienced 82 catheter-related events, such as occlusion, dislodgment, disconnection, or breakage, which required catheter replacement. In the Ascenda group, only 1 patient (1.1\%) was affected by CSF leakage.

CONCLUSIONS To the authors' knowledge, this study is the first in the literature to compare the performance of the new Ascenda catheter, introduced in 2011, with the traditional silicone catheter for intrathecal drug infusion. In their analysis, the authors found that the Ascenda catheter can reduce major complications related to the catheter after ITB pump implantation. Further investigation is necessary to expand on and confirm their results.

http://thejns.org/doi/abs/10.3171/2016.4.PEDS15646

KEY WORDS intrathecal baclofen; complications; pediatric patient; Ascenda catheter; functional neurosurgery

I N June 1996, the US Food and Drug Administration approved the use of intrathecal baclofen for the treatment of spasticity of cerebral origin, and in recent decades intrathecal baclofen therapy (ITB) has been increasingly used to treat spasticity and dystonia., ${ }^{4,6,10,13,22,23}$ In particular, cerebral palsy (CP), ${ }^{9}$ with an incidence of 2.18 cases per 1000 live births, ${ }^{11-18}$ represents one of the most common etiologies. ${ }^{6,9,13,14}$ Over the years, a wide variety of implantation techniques and large differences in complication rates have been observed. ${ }^{1-3,5,14,16,19,21,23}$ Surgical complications related to ITB pump implantation can be reduced by following best practice guidelines for surgical pump implantation, published in $2006,{ }^{1}$ as well as appropriate patient management. Despite the significant benefits provided by this therapy, the literature shows that ITB can be associated with complications related to the surgical

ABBREVIATIONS CP = cerebral palsy; CSF = cerebrospinal fluid; GMFCS = Gross Motor Function Classification System; ITB = intrathecal baclofen therapy; PET = polyethylene terephthalate.

SUBMITTED November 5, 2015. ACCEPTED April 21, 2016.

INCLUDE WHEN CITING Published online June 24, 2016; DOI: 10.3171/2016.4.PEDS15646. 
procedures, the device, or the administered drug (for example, hypotonia, somnolence, headache, nausea, urinary retention, or dizziness) ${ }^{22}$ and the effects due to overdose or withdrawal.

In this study we analyzed complications related to surgical procedures and device problems, dividing them into major complications, defined as events that required a surgical intervention to resolve, and minor complications, defined as events that did not require a surgical procedure. We also noted infections, catheter-related problems, and cerebrospinal fluid (CSF) leaks. Our findings were focused on technical problems and CSF leaks directly related to the catheter.

In the present article we describe complications that occurred in 508 patients treated with ITB from 1998 until August 2014 before and after the introduction, in September 2011, of the new Ascenda intrathecal catheter (Medtronic Inc.), which has an innovative design compared with the silicone catheter.

\section{Methods \\ Clinical Approach}

This work was performed at the pediatric orthopedic department at the "V. Buzzi" Children's Hospital in Milan, Italy. Our center takes a multidisciplinary approach to patient management and is specialized in the treatment and correction of orthopedic deformities due to neurological disorders of childhood and development. Procedures for implantation of an ITB system are usually performed by the same surgeon (F.M.).

Patient selection for ITB is currently performed according to the treatment guidelines provided by Dan et al., ${ }^{6}$ while patient management and clinical procedures have been standardized over the years, taking into consideration the available best practices. Patients selected for ITB, or their parents, sign an informed consent form and their data are registered in a database.

Collected data included product-related and clinical information assessed at baseline and at follow-up visits by means of validated scales specifically selected according to diagnosis, patient age, Gross Motor Function Classification System (GMFCS) level, ${ }^{17}$ and functional and clinical conditions. The GMFCS is a 5-level classification system that describes gross motor function in patients with $\mathrm{CP}$ on the basis of self-initiated movement.

\section{Surgical Procedure}

The procedure was performed under fluoroscopy with the patient under general anesthesia. Via a paramedian oblique approach, the needle was inserted into the intrathecal space at an angle of approximately $30^{\circ}$, until the dura was penetrated. After removing the stylet, we injected $5 \mathrm{ml}$ of normal saline intrathecally to decrease the incidence of post-dural puncture headache, ${ }^{8}$ and the catheter was guided along the vertebral canal up to the appropriate level for the intended therapeutic aim. We then prepared the anchor site by making an incision at the needle site to expose the fascia. For implants with the Ascenda catheter, we located the anchor dispenser and released the anchor. The silicone catheter did not have an anchor dispenser.
After preparing the subfascial pocket, the pump segment of the catheter was tunneled and then connected to the spinal segment; subsequently, the catheter was connected to the pump and internalized.

The procedure for pump placement was modified in March 2003. Previously, the pump had been placed in a subcutaneous abdominal pocket, whereas later it was placed more deeply into the abdomen, under the external oblique muscle and the abdominal rectus. This different procedure was intended to minimize infection risk and pump decubitus that might occur. ${ }^{16}$ In addition, to minimize infection, we also introduced a preoperative prophylaxis protocol including antibiotic administration for 48 hours and antibacterial washing with iodopovidone the evening before the procedure and before entering the operating room.

All patients were implanted with a SynchroMed EL or SynchroMed II programmable pump (Medtronic Inc.). The intrathecal catheters used were the InDura intrathecal catheter (model 8709SC, Medtronic Inc.) and, since September 2011, the new Ascenda intrathecal catheter (model 8780, Medtronic Inc.; https://professional. medtronic.com/pt/neuro/itb/prod/ascenda-intrathecalcatheter/index.htm).

The Ascenda intrathecal catheter body provides increased resistance to kinking, cuts, occlusions, and leaks when exposed to tensile and compressive forces. The increase in the overall strength and durability of the catheter is achieved by an inner lumen of silicone tubing covered by a thermoplastic polyethylene terephthalate (PET) braid and a polyurethane outer jacket. The Ascenda catheter features a unique 4-layer design to prevent collapse, kinking, and occlusion. A PET braid serves as a flexible endoskeleton within the catheter to distribute force. The inner silicone tubing used in the Ascenda catheter is made of the same material used in the InDura catheter (model 8709SC). Reducing the outer diameter without minimizing the strength and long-term performance of the catheter is achieved by pairing polyurethane $80 \mathrm{~A}$ and 55D. Table 1 shows the materials and benefits of the Ascenda catheter.

\section{Significant Complications}

We defined major complications as events that required surgical intervention and minor complications as events that resolved spontaneously and did not require a surgical procedure. The 3 most common complications of ITB are infection, CSF leakage, and catheter-related problems. ${ }^{1}$ Infection is the most serious complication, commonly due to Staphylococcus aureus, and usually requires system explantation and the administration of intravenous antibiotics.

A CSF leak is defined as a CSF leak from the thecal sac. It appears as subcutaneous swelling posteriorly beneath the lumbar incision, anteriorly over and around the pump, or both and usually develops within the first 2 weeks after surgery. Usually patients with CSF leaks are symptom free but have visible and palpable signs, such as swelling. Cerebrospinal fluid leakage can be solved in 3 ways: with bed rest and abdominal pressure dressing; with bed rest, abdominal pressure dressing, and acetazolamide 
TABLE 1. Material and benefits of the Medtronic Ascenda catheter

\begin{tabular}{ll}
\multicolumn{1}{c}{ Material } & \multicolumn{1}{c}{ Benefit } \\
\hline Silicone 4719 & Drug compatible \\
\hline PET braid & Catheter flexibility \& force distribution \\
\hline Polyurethane 80A & Catheter flexibility \\
\hline Polyurethane 55D & $\begin{array}{l}\text { Contributes to overall stiffness; cut resistant; re- } \\
\text { sistant to in vivo environmental stress cracking }\end{array}$ \\
\hline
\end{tabular}

infusion; or with blood patch if the nonsurgical solutions do not work. In cases of an open wound, it is advisable to use glue or sutures.

Device problems are those related to the catheter, which could leak, break, tear, kink, or disconnect, resulting in an underdosage or abrupt cessation of ITB.,15,20,22 These problems can be observed through radiography or contrast injection. The pump itself could flip over in the pocket with the anterior surface faced posteriorly. In this case the pump could be surgically secured to the fascia.

As regards infections and CSF leakage, these events usually occur in the 2 weeks after surgery, while catheterrelated problems occur later. ${ }^{16}$

\section{Data Collection and Analysis}

We examined data related to major and minor complications occurring in our population. Our analysis included data on patients affected by events as well as the total number and details of the events that occurred. In assessing major complications, we compared the 2 groups of patients who had received implants with either the silicone or the Ascenda catheter. Continuous data were presented as the mean \pm standard deviation. Categorical variables were presented as the absolute and relative frequency, and differences between groups were evaluated with the Fisher exact test and chi-square test. A p value $<0.005$ was considered statistically significant.

\section{Results}

\section{Overall Characteristics}

The study population was composed of 508 consecutive patients followed up for a mean of $8.4 \pm 4.6$ years (minimum 0.41 years, maximum 16.22 years). There were 312 males and 196 females, with a mean age at implantation of $13.41 \pm 5.8$ years, and the majority (451 patients) were affected by CP (88.8\%). The SynchroMed EL system was implanted in 197 patients, while the SynchroMed II system was implanted in the remainder. In the considered period, 154 patients needed pump replacement due to battery depletion, and the pump was replaced twice in 12 of them. From the beginning of the study period in September 1998 until September 2011, 416 children were implanted with the InDura catheter (model 8709SC); thereafter, 92 patients were implanted with the Ascenda catheter. Table 2 lists the demographics for the 2 patient groups.
TABLE 2. Summary of demographics for the 2 catheter groups

\begin{tabular}{lcc}
\hline \multicolumn{1}{c}{ Variable } & $\begin{array}{c}\text { Silicone } \\
\text { Catheter }\end{array}$ & $\begin{array}{c}\text { Ascenda } \\
\text { Catheter }\end{array}$ \\
\hline No. of patients & 416 & 92 \\
\hline M/F & $259 / 157$ & $53 / 39$ \\
\hline Mean age at implant in yrs (SD) & $13.28(5.8)$ & $14.13(6)$ \\
\hline Mean FU in yrs (SD) & $9.9(3.7)$ & $1.6(0.8)$ \\
\hline Min \& max FU in yrs & $2.04-16.22$ & $0.41-3.24$ \\
\hline CP (\%) & $370(89 \%)$ & $81(88 \%)$ \\
\hline Spastic quadriplegia & 227 & 43 \\
\hline Dystonic quadriplegia & 73 & 9 \\
\hline Spastic-dystonia quadriplegia & 22 & 10 \\
\hline Spastic diplegia & 44 & 19 \\
\hline Hemiplegic syndrome & 4 & 0 \\
\hline FU = follow-up & &
\end{tabular}

\section{Overall Complications}

In the silicone group, 120 patients had a major complication (29\%), and in the Ascenda group, 1 patient (1.1\%) had a complication $(\mathrm{p}<0.001$, Fisher exact test; Table 3). Table 4 shows the details for each group, and Table 5 shows the summary of major and minor complications.

\section{Infections}

In the non-Ascenda group, infections were present in 43 patients for a total of 45 events, while no infectious events occurred in the Ascenda group. The consistent use of the subfascial technique and the preoperative prophylaxis protocol since March 2003 probably contributed to a constant decrease in infections. In the Ascenda group, which was subsequent to the silicone group, all patients were implanted according to this procedure. Note that the infection is not related to the implantation of the new catheter but only to the surgical technique; thus, the data related to infection have been inserted in the analysis only as clinical data.

\section{Cerebrospinal Fluid Leakage}

As regards CSF leakage as a major complication, we found 23 patients $(5.5 \%)$ in the non-Ascenda group who were affected. The leak was usually treated with 1 or more venous patches, but in 3 cases the system was explanted. In the Ascenda group, only 1 patient $(1.1 \%)$ had a CSF leak, which led to system explantation $(p<0.005)$.

TABLE 3. Patients with major complications in the 2 catheter groups*

\begin{tabular}{crcc}
\hline Group & w/ Event & w/o Event & Total \\
\hline Silicone catheter & 120 & 296 & 416 \\
\hline Ascenda catheter & 1 & 91 & 92 \\
\hline
\end{tabular}

* Significant difference between the 2 catheter groups as regards major complications ( $p<0.001$, Fisher exact test). 
TABLE 4. Patients and events of major complications in the 2 catheter groups

\begin{tabular}{cccccc}
\hline & \multicolumn{2}{c}{ Silicone Group } & & \multicolumn{2}{c}{ Ascenda Group } \\
\cline { 2 - 3 } \cline { 5 - 6 } Major Complication & $\begin{array}{c}\text { No. of } \\
\text { Patients }\end{array}$ & $\begin{array}{c}\text { No. of } \\
\text { Events }\end{array}$ & & $\begin{array}{c}\text { No. of } \\
\text { Patients }\end{array}$ & $\begin{array}{c}\text { No. of } \\
\text { Events }\end{array}$ \\
\hline Infection & 43 & 45 & & 0 \\
\hline CSF leakage & 23 & 26 & & 0 \\
\hline Catheter related & 75 & 82 & & 0 \\
\hline Occlusion & & 5 & & 0 \\
\hline Breaking & & 27 & & 0 \\
\hline Dislodgment & & 18 & & 0 \\
\hline Disconnection & & 8 & & 0 \\
\hline Other & & 24 & & 0 \\
\hline
\end{tabular}

In addition, CSF leaks clearing spontaneously without any intervention were not considered a major complication. This occurred in 15 other patients (3.6\%) in the nonAscenda group and in 10 patients (10.9\%) in the Ascenda group ( $\mathrm{p}<0.005$; Table 6).

\section{Catheter Problems}

In the non-Ascenda group, we found 82 catheter-related events, such as occlusion, dislodgment, disconnection, or breakage, in 75 patients (18\%). These events resulted in catheter replacement in 69 patients $(92 \%)$, while in the other 6 cases $(8 \%)$ the catheter was removed with the pump. Seventeen of the 69 patients replaced the catheter with an Ascenda, and no complications were observed. In the Ascenda group, no problems were found.

In the data we collected, the revision/replacement or removal time and not the onset time of the complication was considered. The number of events that occurred on an annual basis for the entire study interval is shown in Table 7.

\section{Discussion}

Intrathecal baclofen therapy is an effective treatment for managing spasticity of different origins; however, complications related to the device or the administered drug are known to occur and must be managed..$^{16}$ Among all complications, most are catheter related. This can be confirmed thanks to analyses performed by the company Medtronic, which annually publishes results on their own product performance (http://professional.medtronic.com/ performance).

In this study we analyzed 508 consecutive pediatric pa-

TABLE 5. Patients with major and minor complications in the 2 catheter groups*

\begin{tabular}{lccc}
\hline Group & Major Complication & Minor Complication & Total \\
\hline Silicone catheter & 120 & 15 & 135 \\
\hline Ascenda catheter & 1 & 10 & 11 \\
\hline * Significant difference in minor and major complications between the 2 \\
catheter groups ( $p<0.005$, Fisher exact test).
\end{tabular}

TABLE 6. Patients with CSF leakage as a minor complication in the 2 catheter groups*

\begin{tabular}{lccc}
\hline Group & w/ CSF Leakage & w/o CSF Leakage & Total \\
\hline Silicone catheter & 15 & 401 & 416 \\
\hline Ascenda catheter & 10 & 82 & 92 \\
\hline * Significant difference in minor complications between the 2 catheter groups \\
$(p<0.005$, chi-square test).
\end{tabular}

tients who had undergone ITB system implantation in our department for the treatment of spasticity and/or dystonia and compared patients implanted with the standard silicone catheter with those implanted with the new Ascenda catheter. This is the first study to analyze and compare the Ascenda with the traditional intrathecal silicone catheter.

The Ascenda catheter features a unique 4-layer design to reduce catheter problems such as collapse, kinking, and occlusions. There are multiple tests performed on the Ascenda catheter system by Medtronic as part of their design verification process. Design verification testing has been submitted for regulatory review as part of the regulatory approval process and is proprietary to Medtronic. Common catheter-related complications or failure modes include kinking and/or occlusion of the catheter, fractures and breaks of the catheter, and dislodgment of the catheter from the intrathecal space. A majority of the tests measure performance against these catheter complications to confirm Ascenda catheter robustness and reliability. To date, only one test has been published, and it assesses Ascenda catheter performance against the dislodgment failure mode in particular. ${ }^{12}$ Adverse events related to the catheter were the most frequent, and their frequency was similar to rates reported by other authors.

Our previous work ${ }^{16}$ revealed that the majority of events occur during the first 12 months after implantation, while the number of patients with a complication related to the catheter decreases in the following years. This may be explained by the fact that a certain time interval is required before catheter stabilization in the intrathecal space. With this assumption, which indicates that the critical period is represented by the first 12 months, the 2 groups are com-

TABLE 7. Annualized catheter events

\begin{tabular}{cc}
\hline FU After Surgery & No. of Events \\
\hline$<1 \mathrm{yr}$ & 25 \\
\hline $1 \mathrm{yr}$ & 11 \\
\hline $2 \mathrm{yrs}$ & 10 \\
\hline $3 \mathrm{yrs}$ & 8 \\
\hline $4 \mathrm{yrs}$ & 4 \\
\hline $5 \mathrm{yrs}$ & 8 \\
\hline $6 \mathrm{yrs}$ & 8 \\
\hline $7 \mathrm{yrs}$ & 2 \\
\hline $8 \mathrm{yrs}$ & 3 \\
\hline $9 \mathrm{yrs}$ & 1 \\
\hline $10 \mathrm{yrs}$ & 2 \\
\hline
\end{tabular}


parable despite the different mean follow-up periods. Further investigation is necessary to expand and confirm our results.

The large number of treated patients, the long followup period, and the standardization of clinical and technical procedures according to available guidelines and best practices allowed a reliable description of the complications that occurred.

As regards CSF leakage, we observed its decrease as a major complication, defined as a complication that requires surgical intervention to be resolved, versus its increase as a minor complication. The relatively high rate of this major complication in the non-Ascenda group may be explained by the larger size of the Tuohy needle used to insert the traditional silicone catheters. Tuohy needles used for the silicone catheter are 15 gauge, whereas the Tuohy needles used to insert the Ascenda catheter are smaller, that is, 16 gauge.

As regards technical catheter-related problems, the significant reduction in complications could be explained by the innovative design of the Ascenda catheter, with its new 4-layer structure designed to reduce kinks, breaks, leaks, and occlusions. A break is generally caused by fatigue due to forces placed on the catheter during anatomical motions throughout the life of the implanted catheter. The Ascenda has greater overall strength and improved resistance to cuts, breaks, or fractures as a result of the stronger properties in the catheter's polyurethane layer.

Dislodgment, as observed in the clinical setting, is a result of the relative motion between the fascia and skin acting on the catheter and anchor. Possible modes of catheter dislodgment are migration of the catheter relative to the fascia, distal to the anchor, and migration of the catheter relative to the anchor due to forces applied during anatomical movement. Current catheter models use a subcutaneous anchor to stabilize the catheter and prevent dislodgment. After the catheter has been inserted into the intrathecal space, the anchor is sutured where the catheter exits the fascia. Despite this prevention technique, dislodgment can still occur. The Ascenda catheter allows easier insertion into the fascia for secure placement given its unique anchor dispenser and eliminates catheter migration through the anchor, which is securely placed by the new anchor dispenser.

Catheter occlusion occurs when the catheter lumen is blocked. Different actions can cause an occlusion during the implant assembly process, such as sutureless pump connector misalignment, pump port puncture to catheter tubing leading to occlusion within the pump connector, or catheter connector pin puncture. The Ascenda catheter prevents partial or full occlusion of the catheter's inner lumen through the use of a layer of PET braid. When exposed to cyclic fatigue forces, compressive loading forces, and rotational forces, the inner lumen of the catheter remains open. Instead of concentrating applied loads, the PET braid distributes the load.

\section{Conclusions}

The most delicate component in an implantable drug infusion system has always been the catheter; a dislodg- ment, kink, tear, or break in the catheter could interrupt intrathecal therapy and increase the patient management burden. We are the first to compare the performance of the new Ascenda catheter, introduced in 2011, with the traditional silicone catheter for intrathecal drug infusion. In our analysis, we observed that the Ascenda catheter can reduce major catheter-related complications and CSF leakage after ITB pump implantation. Further investigation is necessary to expand and confirm our results.

\section{References}

1. Albright AL, Ferson SS: Intrathecal baclofen therapy in children. Neurosurg Focus 21(2):e3, 2006

2. Albright AL, Turner M, Pattisapu JV: Best-practice surgical techniques for intrathecal baclofen therapy. J Neurosurg 104 (4 Suppl):233-239, 2006

3. Awaad Y, Rizk T, Siddiqui I, Roosen N, McIntosh K, Waines GM: Complications of intrathecal baclofen pump: prevention and cure. ISRN Neurol 2012:575168, 2012

4. Bonouvrié LA, van Schie PE, Becher JG, van Ouwerkerk WJ, Reeuwijk A, Jeroen Vermeulen R: Effects of intrathecal baclofen on daily care in children with secondary generalized dystonia: a pilot study. Eur J Paediatr Neurol 15:539-543, 2011

5. Borowski A, Littleton AG, Borkhuu B, Presedo A, Shah S, Dabney KW, et al: Complications of intrathecal baclofen pump therapy in pediatric patients. J Pediatr Orthop 30:76-81, 2010

6. Dan B, Motta F, Vles JS, Vloeberghs M, Becher JG, Eunson $\mathrm{P}$, et al: Consensus on the appropriate use of intrathecal baclofen (ITB) therapy in paediatric spasticity. Eur J Paediatr Neurol 14:19-28, 2010

7. Dvorak EM, McGuire JR, Nelson ME: Incidence and identification of intrathecal baclofen catheter malfunction. PM R 2:751-756, 2010

8. Faridi Tazeh-Kand N, Eslami B, Ghorbany Marzony S, Abolhassani R, Mohammadian K: Injection of intrathecal normal saline in decreasing postdural puncture headache. J Anesth 28:206-209, 2014

9. Haranhalli N, Anand D, Wisoff JH, Harter DH, Weiner HL, Blate M, et al: Intrathecal baclofen therapy: complication avoidance and management. Childs Nerv Syst 27:421-427, 2011

10. Hasnat MJ, Rice JE: Intrathecal baclofen for treating spasticity in children with cerebral palsy. Cochrane Database Syst Rev 11:CD004552, 2015

11. Himmelmann K, Hagberg G, Uvebrant P: The changing panorama of cerebral palsy in Sweden. X. Prevalence and origin in the birth-year period 1999-2002. Acta Paediatr 99:1337-1343, 2010

12. Hokanson K, Gjoraas A, Kopp J, Metzler M, Servi A: Test results showing bench reliability on catheter dislodgement for Ascenda, Medtronic Neuromodulation's next generation catheter. PM R 2 (9 Suppl):S157, 2010 (Poster)

13. Hoving MA, van Raak EP, Spincemaille GH, Palmans LJ, Becher JG, Vles JS: Efficacy of intrathecal baclofen therapy in children with intractable spastic cerebral palsy: a randomised controlled trial. Eur J Paediatr Neurol 13:240246, 2009

14. Kolaski K, Logan LR: A review of the complications of intrathecal baclofen in patients with cerebral palsy. NeuroRehabilitation 22:383-395, 2007

15. Miracle AC, Fox MA, Ayyangar RN, Vyas A, Mukherji SK, Quint DJ: Imaging evaluation of intrathecal baclofen pumpcatheter systems. AJNR Am J Neuroradiol 32:1158-1164, 2011

16. Motta F, Antonello CE: Analysis of complications in 430 
consecutive pediatric patients treated with intrathecal baclofen therapy: 14-year experience. J Neurosurg Pediatr 13:301-306, 2014

17. Palisano RJ, Hanna SE, Rosenbaum PL, Russell DJ, Walter SD, Wood EP, et al: Validation of a model of gross motor function for children with cerebral palsy. Phys Ther 80:974985,2000

18. Rethlefsen SA, Ryan DD, Kay RM: Classification systems in cerebral palsy. Orthop Clin North Am 41:457-467, 2010

19. Shirley KW, Kothare S, Piatt JH Jr, Adirim TA: Intrathecal baclofen overdose and withdrawal. Pediatr Emerg Care 22:258-261, 2006

20. Varhabhatla NC, Zuo Z: Rising complication rates after intrathecal catheter and pump placement in the pediatric population: analysis of national data between 1997 and 2006. Pain Physician 15:65-74, 2012

21. Vender JR, Hester S, Waller JL, Rekito A, Lee MR: Identification and management of intrathecal baclofen pump complications: a comparison of pediatric and adult patients. J Neurosurg 104 (1 Suppl):9-15, 2006

22. Ward A, Hayden S, Dexter M, Scheinberg A: Continuous intrathecal baclofen for children with spasticity and/or dystonia: Goal attainment and complications associated with treatment. J Paediatr Child Health 45:720-726, 2009
23. Zdolsek HA, Olesch C, Antolovich G, Reddihough D: Intrathecal baclofen therapy: benefits and complications. J Intellect Dev Disabil 36:207-213, 2011

\section{Disclosures}

The authors report no conflict of interest concerning the materials or methods used in this study or the findings specified in this paper.

\section{Author Contributions}

Conception and design: Motta. Acquisition of data: Motta. Analysis and interpretation of data: Motta. Drafting the article: both authors. Critically revising the article: Motta. Reviewed submitted version of manuscript: Motta. Approved the final version of the manuscript on behalf of both authors: Motta. Statistical analysis: Antonello. Administrative/technical/material support: Motta. Study supervision: Motta.

\section{Correspondence}

Francesco Motta, Department of Paediatric Orthopaedics, "V. Buzzi” Children's Hospital, Via Castelvetro 32, Milan 20154, Italy. email: f.motta@icp.mi.it. 